\title{
Diagnosis of hyperpotassemia on electrocardiography in a young woman with adrenal insufficiency
}

\author{
Mehmet Emin Piskinpasa a ${ }^{a}$ Turgut Karabag ${ }^{b, *}$, Burcugül Kaya ${ }^{a}$, Yalcin Hacioglu ${ }^{c}$, Fettah Sametoglu ${ }^{a}$ \\ a Department of Internal Medicine, Istanbul Education and Research Hospital, Istanbul, Turkey \\ ${ }^{b}$ Department of Cardiology, Istanbul Education and Research Hospital, Istanbul, Turkey \\ c Department of Family Medicine, Istanbul Education and Research Hospital, Istanbul, Turkey
}

\section{A R T I C L E I N F O}

\section{Article history:}

Received 26 June 2016

Received in revised form 9 September 2016

Accepted 9 September 2016

Available online 17 September 2016

\section{Keywords:}

Hyperpotassemia

Adrenal insufficiency

Electrocardiography

\section{Introduction}

Severe hyperpotassemia is defined as a serum potassium level $(\mathrm{K}+)$ of $6.0 \mathrm{mmol} / \mathrm{L}$ or greater with electrocardiographic (ECG) changes or a serum potassium level of $6.5 \mathrm{mmol} / \mathrm{L}$ or greater without ECG changes. ${ }^{1}$ Hyperpotassemia is caused by an inability of the kidneys to excrete potassium and/or the impairment of mechanisms that transport potassium from the circulation into the cells. Acute episodes of hyperpotassemia are usually triggered by the introduction of a medication that can affect potassium homeostasis, an illness, or dehydration. ${ }^{2}$ Hyperpotassemia can cause various changes ranging from nonspecific changes on ECG to fatal cardiac arrhythmias. ${ }^{3}$ Emergency treatment is necessary to prevent the development of fatal arrhythmias. This report presents the case of a young patient presenting with acute adrenal insufficiency who developed hypotension, hyponatremia and hyperpotassemia and discusses hyperpotassemia-induced ECG changes and treatment methods.

\section{Case report}

A 21-year old female patient with no previous disease presented to the emergency department with complaints of fatigue, dizziness, indigestion, and heartburn. The patient reported having lost $15 \mathrm{~kg}$ of weight within the last 6 months and had increased pigmentation of the skin

\footnotetext{
* Corresponding author at: Istanbul Eğitim Araștırma Hastanesi, Kardiyoloji Bölümü, Kat:6 Samatya-fatih, İstanbul, Turkey.

E-mail address: turgutkarabag@hotmail.com (T. Karabag).

Peer review under responsibility of The Society of Cardiovascular Academy.
}

and oral mucosa. The patient was not pregnant and had no history of drug, tobacco or alcohol use. There was no family history of chronic disease. A physical examination showed that blood pressure was $85 / 60 \mathrm{~mm} \mathrm{Hg}$, and heart rate was 96 beats/min. A chest X-ray was unremarkable. There was increased pigmentation in the oral mucosa and various areas of the body. Abdominal examination revealed midline tenderness. There was no defence or rebound. The results of other systemic examinations were normal. Wide QRS complexes were recorded on ECG. The rhythm was atrioventricular rhythm with peaked T-waves, and QRS complexes had merged with the S-wave (Fig. 1). Laboratory results conducted on venous blood sample revealed that potassium was $8.3 \mathrm{mmol} / \mathrm{L}$ and sodium was $118 \mathrm{mmol} / \mathrm{L}$. Blood gas analysis showed a pH of 7.25 and bicarbonate of 14 . Blood glucose was $72 \mathrm{mg} / \mathrm{ld}$. The patient was hospitalized with initial diagnoses of adrenal insufficiency and acute adrenal crisis for further investigation, observation and treatment. Hyperpotassemia was planned to be treated first. Accordingly, the patient was given 1 ampule $(225 \mathrm{mg}$ ) of calcium gluconate. Subsequently, 20\% dextrose buffered with insulin was infused. Further examination of the patient revealed decreased cortisol $(1.96 \mu \mathrm{g} / \mathrm{mL})$ and increased ACTH. (60 pg/ml). Her thyroid function test and parathormone level were normal. The synacthen test showed low cortisol level $(7 \mu \mathrm{g} / \mathrm{mL})$. Antinuclear antibodies and anti-DNA antibodies were negative. Other laboratory findings were unremarkable. Abdominal ultrasound and tomography were unremarkable. Cranial magnetic resonance imaging revealed no evidence to suggest hypophyseal tumour or Sheehan Syndrome. The final diagnosis was primary adrenal insufficiency. The patient was given potassium lowering therapy (20\% dextrose buffered with insulin) as well as $500 \mathrm{mg}$ of sodium hydrogen carbonate and $20 \mathrm{mg}$ of methylprednisolone for 4 days. A follow-up examination after 2 days revealed a potassium level of $7.2 \mathrm{mmol} / \mathrm{l}$, and a sodium level of $118 \mathrm{mmol} / \mathrm{l}$, upon which, methylprednisolone was administered as $40 \mathrm{mg}$ for 4 days. In addition, fludrocortisone was administered in a dose of $0.4 \mathrm{mg}$. There was no change in sodium level on day $4(122 \mathrm{mmol} / \mathrm{L})$ but potassium level was $5.7 \mathrm{mmol} / \mathrm{L}$. At the 4-day follow-up, an ECG showed normal sinus rhythm. The PR interval and QRS duration were normal (Fig. 2).

\section{Discussion}

Hyperpotassemia is a medical emergency that requires rapid diagnosis and treatment ${ }^{4}$. Hyperpotassemia is usually associated with 

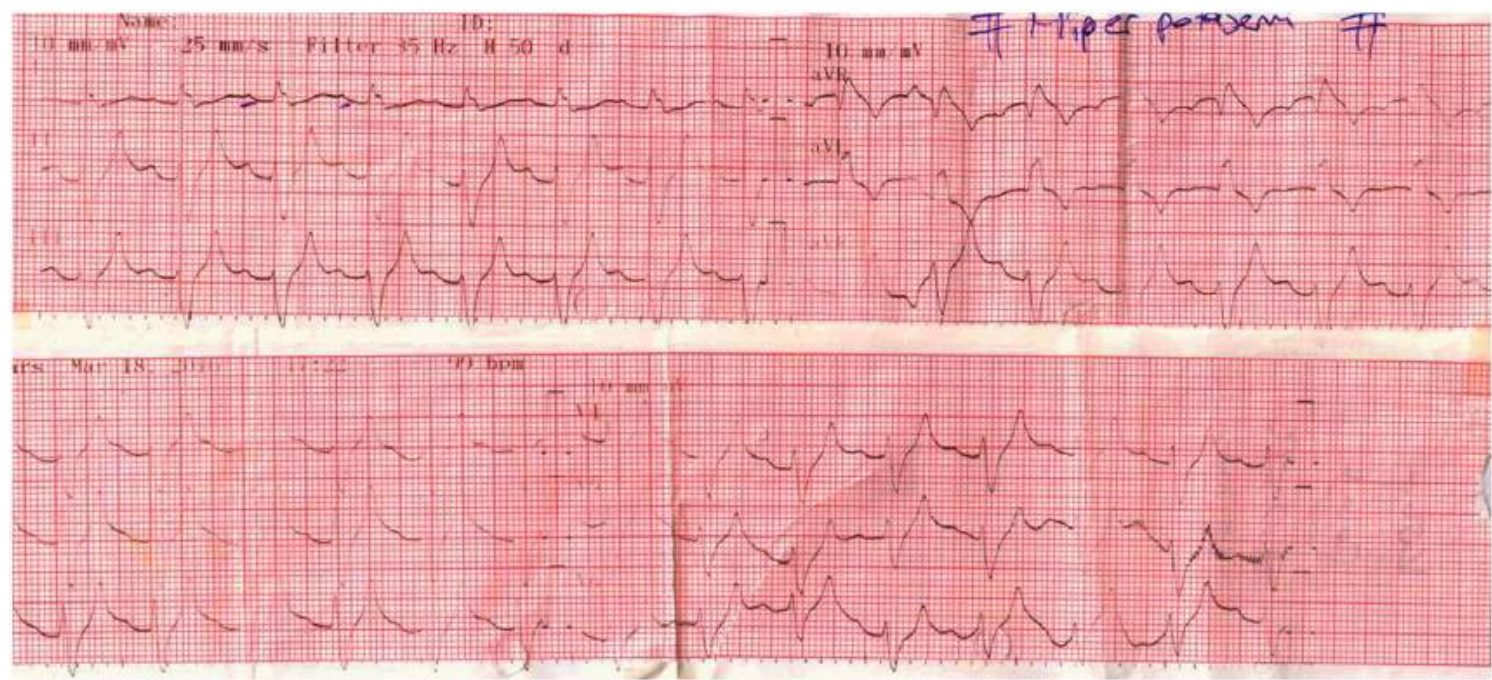

Fig. 1. Electrocardiograph showing idioventricular rhythm in a 21-year-old woman with $8.3 \mathrm{mmol} / \mathrm{L}$ potassium.

various ECG changes and these changes can be used to follow the effects of potassium on the heart ${ }^{5}$. As serum level of potassium increases, transmembrane permeability of cardiac cells also increases and potassium influx into the cells occurs. As a result, the resting membrane potential is less negative, the action potential is shortened, and conduction between myocytes is suppressed. ${ }^{6}$ As potassium levels rise above normal, the earliest ECG change is usually peaked, symmetric, narrowbased $\mathrm{T}$. waves. ${ }^{7}$ A further increase in potassium levels results in declined conduction velocity, widened and flattened P wave, lengthened PR segment and wide QRS complex with slurring of the $S$ wave into a rapidly ascending limb of the T wave. P wave disappears and the QRS complex resembles "sine wave" that may result in ventricular fibrillation or asystole. ${ }^{7}$ In the case presented here, the potassium level was $8.3 \mathrm{mmol} / \mathrm{L}$. An electrocardiogram showed flattened P waves as well as peaked T waves. The PR interval was lengthened and there were wide QRS complexes reaching $0.16 \mathrm{~s}$ in some leads and the $\mathrm{S}$ wave of the QRS complex had merged with the ascending limb of the $\mathrm{T}$ wave. We considered that the clinical picture of the young patient with no previous structural heart disease and electrolyte imbalance resulting in abnormal ECG were associated with adrenal insufficiency.
The physical examination and ECG findings were of guidance in establishing the aetiological diagnosis of primary adrenal insufficiency.

In the emergency treatment of hyperpotassemia, intravenous calcium gluconate and insulin-buffered hypertonic glucose facilitate the transport of potassium from the extracellular space into the cells. Intravenous sodium bicarbonate can also be useful. The sodium-cycle cation exchange resin polystyrene sulfonate given with $70 \%$ sorbitol as a retention enema is usually the next step and if necessary can be followed by oral doses ${ }^{8,9}$. It is also of significant importance to treat the primary cause of hyperpotassemia. In our patient, even though calcium gluconate and insulin-buffered gluconate led to a decrease in potassium levels, the most effective decrease appears to have been observed after steroid replacement.

In conclusion, hyperpotassemia is an important clinical condition that requires urgent diagnosis and treatment. ECG findings play an important role in diagnosis and treatment in patients with hyperpotassemia, particularly in patients presenting with nonspecific symptoms. Echocardiographic findings can be of great help in diseases presenting with various nonspecific symptoms such as adrenal insufficiency, as in the case presented here.
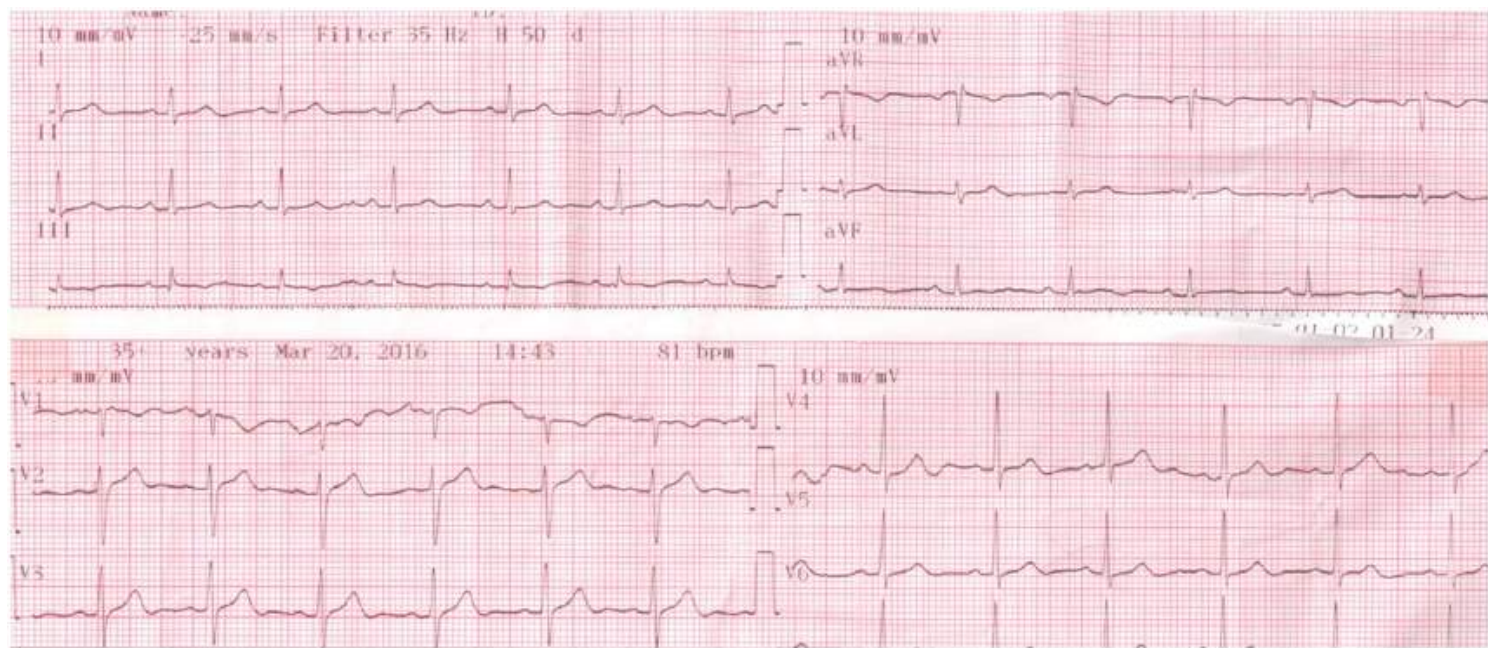

Fig. 2. Electrocardiograph after the treatment (potassium level $5.7 \mathrm{mmol} / \mathrm{L}$ ). 


\section{References}

1. Nyirenda MJ, Tang JI, Padfield PL Seckl JR. Hyperpotassemia. BMJ 2009;339:b4114.

2. Hashem A. Hyperkalemia revisited. Saudi J Kidney Dis Transpl 2007;18(4):577-584

3. Chon SB, Kwak YH, Hwang SS, Oh WS, Bae JH. Severe hyperkalemia can be detected immediately by quantitative electrocardiography and clinical history in patients with symptomatic or extreme bradycardia: a retrospective cross-sectional study. J Crit Care 2003;28:1112.e7-1112.e13.

4. Massin MM. Visual diagnosis of severe hyperkalemia in a young infant. Pediatr Cardiol 2012:33:1216-1217.

5. Khattak HK, Khalid S, Manzoor K, Stein PK. Recurrent life-threatening hyperkalemia without typical electrocardiographic changes. J Electrocardiol 2014;47:95-97.
6. Diercks DB, Shumaik GM, Harrigan RA, Brady WJ, Chan TC. Electrocardiographic manifestations: electrolyte abnormalities. J Emerg Med 2004;27:153-160.

7. Kawji MM, Glancy DL. Electrocardiogram in a 35-year-old man. Am J Cardiol 2015;116 162

8. VanderArk CR, Balantyne F, Reynolds Jr EW. Electrolytes and the Electrocardiogram. In: Fisch C, editor. Complex Electrocardiography. Philadelphia: FA Davis; 1973. p. 269-294.

9. Marriott HJL. Emergency Electrocardiography: A Vademecum for Every Caretaker of Cardiac Crises. Naples, FL: Trinity Press; 1997;47-48. 